\title{
Pemodelan Penurunan Tekanan Brine di Dalam Pipa Injeksi pada Lapangan Panas Bumi Dieng
}

\section{Jeferson Poliia*} aJurusan Fisika, Peminatan Geotermal, FMIPA, Universitas Negeri Manado

KA T A K U N I

Penurunan tekanan

Panas bumi

Injeksi Brine

\begin{abstract}
A B S T R A K
Injeksi brine hasil dari fluida produksi panas bumi digunakan untuk mengisi volume pori batuan reservoir, mencegah penurunan tekanan batuan yang terlalu cepat, dan mencegah polusi panas dan polusi kimia pada lingkungan yang disebabkan oleh kandungan kimia tertentu pada brine. Pada pipa aliran brine terjadi penurunan tekanan fluida sepanjang aliran. Di lapangan panas bumi Dieng, konsentrasi silika sangat tinggi, sehingga penurunan temperatur saturasi memicu desposisi silika. Penurunan tekanan sepanjang pipa aliran brine dari pompa Vertikal Atas (VA) 7 ke pond di pad 29 di lapangan panas bumi Dieng akan menyebabkan penurunan temperatur saturasi, selain juga kehilangan panas secara alami. Perhitungan penurunan tekanan fluida brine berdasarkan perhitungan Harrison-Freeston dan metode dari Zhao, yang dikembangkan dengan algoritma menggunakan Macro Excel. Sehingga dengan memodelkan penurunan tekanan sepanjang pipa alir, dapat dikembangkan untuk perhitungan penurunan temperatur dan pengendapan silika di pipa aliran brine untuk injeksi panas bumi.
\end{abstract}

KEYW OR D S

Pressure Drop

Geothermal

Brine Injection

\begin{abstract}
A B S T R A C T
Brine injection from geothermal production fluids is used to fill reservoir pore rock volumes, preventing rapid rock pressure drops, and preventing heat pollution and chemical pollution in the environment caused by certain chemical constituents in the brine. Decrease fluid pressure along the flow on the brine flow pipe. In the Dieng geothermal field, the silica concentration is very high, so the decrease in saturation temperature triggers the silica desposition. The pressure drop along the brine flow pipe from the Upper Vertical (VA) 7 pump to the pond in pad 29 in Dieng geothermal field will cause a decrease in saturation temperature, as well as natural heat loss. The calculation of the decrease in brine fluid pressure based on Harrison-Freeston calculations and methods of Zhao, developed with algorithms using Macro Excel. By modeling the pressure drop along the flow line, it can be developed for the calculation of temperature drop and deposition of silica in the brine flow pipe for geothermal injection
\end{abstract}

TERSEDIAONLINE

1 Agustus 2017

\section{Pendahuluan}

Sistem panas bumi di Indonesia pada umumnya merupakan sistem hidrotermal bertemperatur tinggi (di atas $225^{\circ} \mathrm{C}$ ).Lapangan panas bumi Dieng termasuk dalam sistem ini.Menurut Hochstein dan Browne (2000), sistem hidrotermal dapat didefinisikan sebagai sistem perpindahan panas bumi dari sumber panas (biasanya cooling pluton) ke permukaan dengan konveksi bebas, dengan melibatkan fluida meteorik disertai atau tanpa fluida magmatik.Sistem panas bumi hidrotermal dapat diilustrasikan seperti pada gambar 1.

*Corresponding author: Jurusan Fisika FMIPA UNIMA, Jl. Tondano, Sulawesi Utara 95618; Email address: jeferson.polii@gmail.com

Published by FMIPA UNSRAT (2017) 


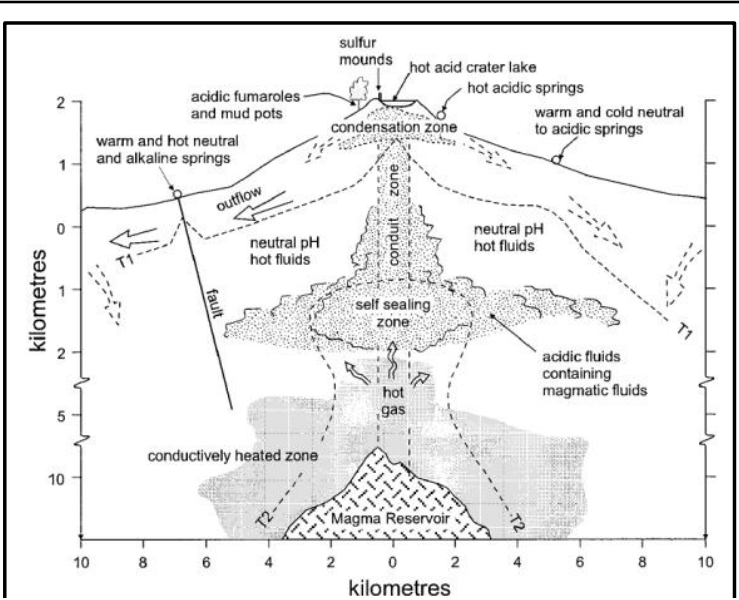

Gambar 1 Sistem Panas Bumi Hidrotermal

(Sumber : Hochstein dan Browne, 2000)

Model sistem panas bumi hidrotermal menjadi prospek jangka panjang jika didukung oleh 5 aspek penting berikut.

1. Sumber panas bumi yang besar

2. Reservoir yang permeabel

3. Adanya aliran air

4. Lapisan penudung (cap rock)

5. Mekanisme peresapan

Kelima aspek tersebut saling membangun dan membentuk sistem panas bumi hidrotermal yang dapat dieksploitasi. Kurangnya salah satu aspek akan membuat lapangan pada sistem panas bumi ini tidak dapat dieksploitasi. Misalnya tanpa sumber panas yang besar, fluida panas yang dihasilkan akan memiliki temperatur yang rendah menyebabkan eksploitasi untuk jangka panjang menjadi tidak efisien. Reservoir yang tidak permeabel akan menyebabkan aliran fluida tidak lancar di dalam reservoir sehingga produksi fluida panas bumi tidak dapat dilakukan. Tidak adanya aliran air menyebabkan tidak adanya perpindahan panas dari formasi batuan yang mengandung panas di reservoir. Tanpa adanya cap rock yang impermeabel akan menyebabkan fluida panas bumi keluar sebagai manifestasi permukaan dan tekanan formasi menjadi cepat menurun. Sedangkan jika tidak adanya peresapan air ke reservoir yang cukup akan mengakibatkan fluida panas bumi menurun produksinya dan berdampak pada kemampuan pembangkitan listrik yang menggunakan fluida panas bumi. Peresapan air ke dalam reservoir dapat dilakukan dengan menginjeksikan fluida brine ke reservoir (Di Pippo, 2008).

Untuk mengatasi penurunan produksi massa yang disebabkan oleh turunnya tekanan di reservoir maka digunakan teknik injeksi. Injeksi fluida dilakukan dengan tujuan mengisi kembali volume pori batuan dan mencegah penurunan tekanan batuan yang terlalu cepat. Selain itu, injeksi fluida berfungsi untuk mencegah polusi panas dan juga polusi kimia pada lingkungan yang disebabkan oleh kandungan kimia tertentu pada brine hasil injeksi.Letak sumur injeksi umumnya cukup jauh dari sumur produksi, biasanya pada daerah batas reservoir.Hal ini untuk menghindari thermal breakthrough dan penurunan temperatur yang drastis pada sumur produksi (Sanyal, 1995).

Penurunan tekanan fluida terjadi di sepanjang pipa injeksi diakibatkan oleh gesekan partikel dalam fluida, akselerasi gerak fluida, dan elevasi pipa alir. Penurunan tekanan akan berdampak pada temperatur saturasi fluida brine. Brine di lapangan panas bumi Dieng mengandung silika yang terdeposisi ketika mengalami penurunan temperatur. Sehingga pemodelan penurunan tekanan sepanjang pipa alir injeksi brineakan membantu teknisi dan sainstis dalam memprediksi gejala fisis maupun deposisi silika sepanjang pipa injeksi.

\section{Metode Perhitungan Penurunan Tekanan}

Persamaan dasar untuk penurunan tekanan (pressure drop) adalah

$$
\left(\frac{d p}{d z}\right)_{\text {total }}=\left(\frac{d p}{d z}\right)_{f}+\left(\frac{d p}{d z}\right)_{g}+\left(\frac{d p}{d z}\right)_{a c c}
$$

Dimana :

$\left(\frac{d p}{d z}\right)_{f} \quad=$ kehilangan tekanan karena gesekan

$\left(\frac{d p}{d z}\right)_{g} \quad=$ kehilangan tekanan karena elevasi

$$
\begin{aligned}
& =5-10 \% \text { dari }\left(\frac{d p}{d z}\right)_{\text {total }} \\
& =\text { kehilangan tekanan karena } \\
& =80-95 \% \text { dari }\left(\frac{d p}{d z}\right)_{\text {total }}
\end{aligned}
$$

$\left(\frac{d p}{d z}\right)_{a c c}=$ kehilangan tekanan karena akselerasi (kecil, sehingga sering diabaikan)

Untuk perhitungan penurunan tekanan, perlu memperhatikan jenis aliran fluida brine yang mengalir dalam pipa.Brine hasil pemisahan di separator umumnya merupakan fluida satu fasa. Tetapi ketika temperatur brine melebihi temperatur saturasinya, terbentuk fraksi uap sehingga brine menjadi fluida dua fasa. Salah satu metode perhitungan penurunan yang dikembangkan olehHarrison dan Freeston (Saptadji, 2001).

Harrison dan Freeston menentukan penurunan tekanan karena gesekan dan akselerasi berdasarkan persamaan berikut :

Dimana :

$$
\left(\frac{d p}{d p}\right)_{f \& a c c}=\frac{4 \tau_{\omega}}{D(1-A C)}
$$

$$
\begin{gathered}
\tau_{\omega}=\frac{\lambda V_{f}^{2}}{8 v_{f}} \\
V_{f}=\frac{m(1-\alpha) v_{f}}{(1-\alpha) A} \\
A=\frac{\pi D^{2}}{4}
\end{gathered}
$$

Dengan $\mathrm{T}_{\omega}$ adalah shear stress, $\lambda$ adalah faktor friksi, $\bar{V}_{f}$ adalah kecepatan fasa fluida, $m$ adalah laju alir brine, AC adalah acceleration correction, A adalah luas penampang pipa dengan diameter dalam D, dan Uf adalah volume spesifik fasa cair.

Faktor friksi $\lambda$ ditentukan dengan metode yang dikembangkan Churchill tahun 1977.Churchill mengembangkan persamaan korelasi tunggal yang 
menghubungkan faktor friksi dengan bilangan Reynold dan kekasaran (roughness) pipa untuk aliran laminar, transisi, atau turbulen.Faktor friksi $\lambda$ dapat diperoleh dengan persamaan berikut (Freeston, 1996).

$$
\lambda=8\left[\left(\frac{8}{R e}\right)^{12}+\frac{1}{(A+B)^{3 / 2}}\right]^{1 / 12}
$$

dengan :

$$
A=\left[2,457 \ln \frac{1}{\left(\frac{7}{R e}\right)^{0,9}+0,27\left(\frac{\varepsilon}{D}\right)}\right]^{16} \text { dan } B=\left[\frac{37530}{R e}\right]^{16}
$$

Dimana $\mathrm{D}$ adalah diameter dalam pipa, $\varepsilon$ adalah kekasaran pipa, dan Re adalah bilangan Reynold.

Bilangan Reynold menunjukkan jenis aliran (laminar, transisi, ataupun turbulen) sangat bergantung pada perbandingan gaya inersia terhadap gaya viskositas fluida. Aliran laminar ditunjukkan dalam bentuk aliran fluida cenderung lurus dengan kecepatan rendah, sedangkan aliran turbulen ditunjukkan dalam bentuk aliran dengan kecepatan berfluktuasi dan bergerak tak beraturan.Untuk aliran dalam pipa, bilangan Reynold dapat diperoleh dari persamaan berikut.

$$
R e=\frac{\rho V_{f} D}{\mu}
$$

Dimana $\rho$ adalah densitas fluida, $V_{f}$ adalah kecepatan fluida, dan D adalah diameter pipa.

Untuk perhitungan praktis, jenis aliran dapat ditentukan dari besarnya bilangan Reynold (Re) yang diperoleh.Aliran laminar jika $\operatorname{Re}<2300$, aliran turbulen jika Re > 10000, dan aliran transisi jika nilai Re berada di antara 2300 dan 10000.

$\alpha$ adalah void friction yang diperoleh dari persamaan :

$$
\alpha=\frac{1}{1+\left(\frac{1-x}{x}\right)^{0.8}\left(\frac{v_{f}}{v_{g}}\right)^{0.515}}
$$

dengan $x$ adalah fraksi uap dan Ug adalah volume spesifik fasa uap.

Perhitungan penurunan tekanan aliran fluida dua fasa memiliki acceleration correction (AC) yang ditunjukkan dengan persamaan :

$$
A C=\frac{m^{2} x^{2} v_{g}}{P A^{2} \alpha}
$$

dimana $\mathrm{P}$ adalah tekanan fluida.

Persamaan untuk penurunan tekanan karena elevasi :

$$
\left(\frac{d p}{d z}\right)_{g}=\rho g \sin \theta
$$

dengan g adalah percepatan gravitasi dan $\rho$ adalah densitas fluida yang diperoleh dari persamaan berikut.

$$
\rho=\alpha \rho_{g}+(1-\alpha) \rho_{f}
$$

dimana $\rho_{\mathrm{f}}$ adalah densitas fasa cair dan $\rho_{\mathrm{g}}$ adalah densitas fasa uap.
Zhao dkk (2000) membuat korelasi baru untuk void fraction $\alpha$. Void fraction ini memberikan kesesuaian yang lebih baik antara data penurunan tekanan hasil prediksi terhadap data hasil pengukuran pada fluida dua fasa yang mengalir dalam pipa. Zhao dkk (2000) memberikan harga void faction ini dalam bentuk persamaan

$$
\frac{1-\alpha}{\alpha^{7 / 8}}=\left[\left(\frac{1}{x}-1\right)\left(\frac{\rho_{g}}{\rho_{f}}\right)\left(\frac{\mu_{f}}{\mu_{g}}\right)\right]^{7 / 8}
$$

Dalam prediksi penurunan tekanan aliran dua fasa, void friction $\alpha$ merupakan parameter fundamental yang penting. Nilai ini mempengaruhi parameter dua fasa lainnya seperti kecepatan fasa cair $V_{f}$ dan densitas fluida brine $\rho$. Zhao dkk (2000) menunjukkan kecepatan fasa cair dalam bentuk persamaan

$$
V_{f}=1.1(1-x) \frac{m(1-x) v_{f}}{(1-\alpha) A}
$$

Besarnya kehilangan tekanan dalam pipa, dapat diperoleh dari persamaan :

$$
\text { Kehilangan tekanan }=\left(\frac{d p}{d z}\right)_{\text {total }} \text { x panjang pipa }
$$

Ketika temperatur brine berada di bawah temperatur saturasi, brine menjadi aliran satu fasa. Perhitungan penurunan tekanan pada brine yang mengalir dalam kondisi compressed liquid tidak memiliki fraksi uap, sehingga perhitungan void fraction $\alpha$ dan acceleration correction AC dapat diabaikan.

\section{Hasil dan Pembahasan \\ Pemodelan Tekanan Brine di dalam Pipa Injeksi}

Pemodelan tekanan dilakukan pada pipa aliran brine dari pompa Vertikal Atas (VA) di pad 7 sampai di pond di pad 29. Pemodelan pipa dilakukan per segmen pipa, dimana segmen pipa dibagi menjadi segmen rata-rata 3 meter berdasarkan elevasinya.Pada masing-masing segmen pipa dilakukan perhitungan penurunan tekanan.Perhitungan dilakukan dengan menggunakan MacroExcel dengan bahasa pemrograman Visual Basic for Application.Untuk memodelkan tekanan, digunakan metode penurunan tekanandari Zhao dkk (2000).Diagram alir perhitungan penurunan tekanan ditunjukkan pada gambar 3.1. Jalur brine ini menggunakan pipa berbahan dasar Carbon Steel dengan diameter 8" dan schedule 40. Tekanan ujung pipa ditetapkan pada tekanan atmosfer karena aliran keluar bebas di pad 29. Dengan asumsi kekasaran pipa konstan, maka dengan menggunakan Solver Excel dihitung laju alir brine yang tepat. 


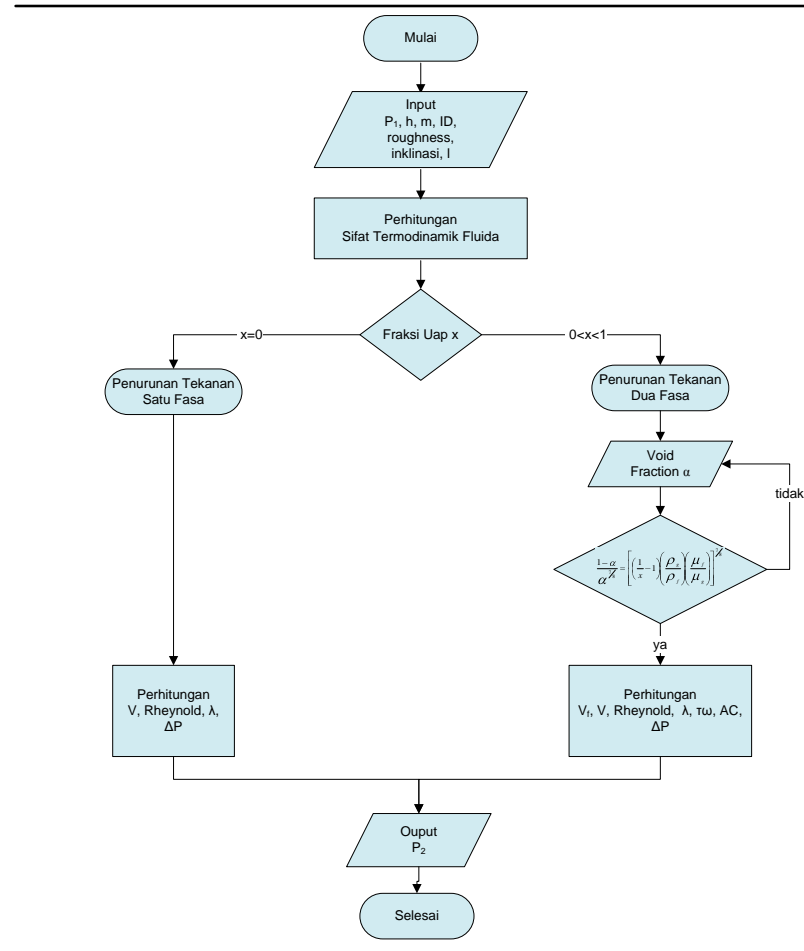

Gambar 2. Diagram Alir Perhitungan Penurunan Tekanan Fluida di Dalam Pipa

Perhitungan menggunakan data pada saat pemasangan pipa aliran brine dari pad 7 ke pad29. Kekasaran pipa Carbon Steel menggunakan data Pipe Absolute Roughness Value sebesar 4,5 x 10-5 m. Pipa Carbon Steel 8 inch dengan schedule 40 memiliki diameter dalam 0,1999 m dan ketebalan pipa 8,2 mm.Untuk perhitungan, kekasaran pipa dianggap konstan. Pompa VA Pad 7 diatur pada tekanan 12,52 Bar. Tekanan di ujung pipa pada pond di pad 29 merupakan tekanan 1 atmosfer, sehingga brine yang mengalir sepanjang pipa dalam kondisi compressed liquid. Hasil perhitungan penurunan tekanan fluida brine di dalam pipa injeksi dari pompa Vertikal Atas (VA) di pad 7 sampai di pond di pad 29 ditunjukkan pada grafik berikut.

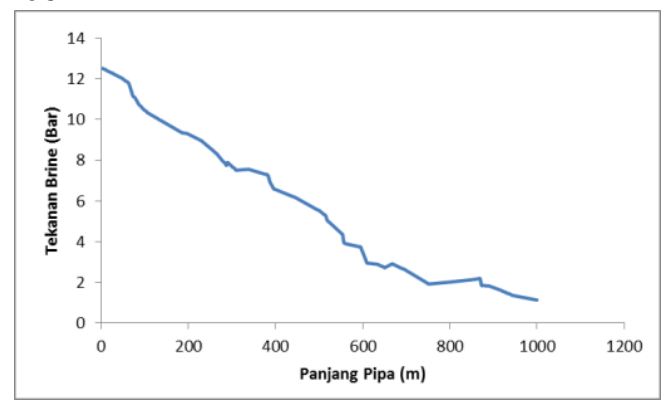

Gambar 3. Penurunan Tekanan Fluida Brine Sepanjang Pipa Injeksi

Fluida brine di lapangan panas bumi Dieng yang mengalir melewati jalur pipa injeksi VA 7 ke pond di pad 29 mengandung silika yang berada pada kondisi jenuh. Sehingga terjadinya penurunan tekanan akan berdampak pada penurunan temperatur saturasi brine, selain kehilangan panas yang terjadi secara alami. Silika yang berada pada kondisi terlarut dalam bentuk amorf akan terdeposisi pada saat penurunan temperatur. Perhitungan nilai tekanan pada masing-masing segmen akan membantu pencegahan penurunan temperatur saturasi dan mengurangi pengendapan silika yang sering menyebabkan penyumbatan pipa aliran brine.

4. Kesimpulan

1. Fluida brine yang mengalir di dalam pipa injeksi dari pompa VA 7 ke pond di pad 29 lapangan panas bumi Dieng dapat dimodelkan penurunan tekanannya dengan diketahui konfigurasi pipa, brine, dan tekanan pompa. Model perhitungan penurunan tekanan fluida brinedikembangkan menggunakan Macro Excel dengan bahasa pemrograman Visual Basic for Application.

2. Hasil perhitungan pemodelan penurunan tekanan fluida brine dapat dilanjutkan untuk memperoleh penurunan temperatur dan desposisi silika yang mengendap di pipa injeksi.

Daftar Pustaka

Di Pippo, R. 2008. Geothermal Power Plants Second Edition, Butterworth-Heinemann, Oxford, UK

Freeston, D. H. 1996.Geothermal Technology : Teaching the Teachers Course Stage 3, Bandung, Indonesia

Saptadji, N. M. 2001.Teknik Panas Bumi, Institut Teknologi Bandung, Bandung, Indonesia

Sanyal, S. K., Granados, E. E., dan Menzies, A. J. 1995.Injection Related Problems Encountered in Geothermal Projects and Their Mitigation The United States Experience, World Geothermal Congress, Florence, Italy

Zhao, H. D., Lee, K. C., dan Freeston, D. H. 2000.Geothermal Two Phase In Flow Horizontal Pipes, Proceedings World Geothermal Congress 2000, Tohoku, Jepang 